\title{
Watkins on Kant's Laws of Nature
}

\author{
JANUM SETHI \\ University of Michigan, Ann Arbor \\ janumset@umich.edu
}

\begin{abstract}
I discuss three sets of worries concerning Watkins' account of laws of nature in Kant on Laws. First, I argue contra Watkins that Kant's laws of nature do not depend on acts of prescription in any literal sense. Second, I question how his generic conception of laws applies to empirical laws of nature and suggest that the worries about unknowability or contingency that he raises for contemporary alternatives may equally arise for empirical laws on Kant's account. Finally, I discuss his claim that Kant's a priori laws depend on the immutability of human cognitive capacities and ask how this immutability should be understood.
\end{abstract}

Keywords: Eric Watkins, laws of nature, empirical laws, cognitive capacities

The notion of a law figures centrally in a wide variety of contexts in Kant's philosophical system. In Kant on Laws (Watkins 20I9), Eric Watkins presents a rigorous treatment of the particular laws that appear in a number of these diverse contexts, while at the same time bringing into view the fundamental conception of law and lawfulness that he argues unites them. The result is a book that is as rich in detail and scope as it is in systematic insight.

In my discussion, I mainly focus on Watkins' treatment of laws of nature. In section I, I raise some worries for Watkins' claim that, on Kant's view, there is a literal sense in which laws are prescribed to nature. In section 2, I consider how Watkins' generic account of laws applies to empirical laws of nature. I argue that, whereas he successfully shows how Kant avoids the twin pitfalls of making a priori laws either contingent or unknowable, these worries threaten to re-emerge for empirical laws. Finally, in section 3, I examine Watkins' claim that for Kant, the necessity of the 
a priori laws of nature depends on the immutability of human cognitive natures. I question how exactly this immutability is to be understood in light of some conflicting passages in the Critique of Pure Reason.

\section{Acts of Prescription}

A framing question that guides Watkins in his development of a univocal concept of law is whether there is a literal sense in which nature can be said to be governed by laws (pp. I $5,22,28$ ). To motivate this question, Watkins reminds readers of the notion of law that grows out of the natural law tradition, according to which a law 'can be established only through the act of a (superior) lawgiver who governs (inferior) subjects' (p. I2). While this notion of law is at home in a political context, it might seem like it is at best metaphorically applicable to laws of nature. Watkins argues, however, that Kant's distinctive account of the latter allows for a non-metaphorical sense in which objects in nature can genuinely be said to be governed by laws that are prescribed to them by the acts of an authoritative lawmaker: human reason itself (pp. 23, 27). This insight underlies Watkins' claim that there is a univocal and non-metaphorical concept of law that applies to all of Kant's laws. According to this concept, a law requires, first, that there be an objective or necessary rule and, second, that this rule be 'prescribed ... to a particular domain' by 'a proper authority' through 'an appropriate act' (p. I4).

Now, it is indeed a distinctive and attractive feature of Kant's account that the universal laws of nature turn out not to be 'brute necessities' that simply obtain in the natural world (p. 278), but rather have their source in the cognitive faculties of rational subjects. A line of objection I want to pursue, however, concerns whether this is sufficient to ground the claim that there is a literal, non-metaphorical sense in which these laws depend on acts of prescription.

A first question that arises is which prescriptive acts Watkins has in mind. At points, it seems that he takes the relevant acts to be particular acts of synthesis or judgement. Thus for example, he says that the understanding legislates to nature in virtue of 'its spontaneous activity of combining representations into a single experience according to its own independent rules' (p. 25; see also pp. 24, 236-7). But what could the 'activity' referred to here consist in besides particular acts of combining representations, carried out, presumably, by particular cognitive subjects? Moreover, Watkins speculates that the legislation of laws of nature may involve a cognitive state (akin to the feeling of respect in moral motivation) that could 'lea[d] one to assent to a priori laws' (p. 24I). This again suggests 
that there is a meaningful sense in which the obtaining of laws of nature depends on the assent of particular subjects, which in turn depends on their being in particular cognitive states.

But this model gives rise to a number of worries. First, it seems contrary to the necessity of laws of nature that their status as laws should depend on the particular cognitive states or acts of particular subjects. Second, it is hard to see how a priori laws like the law of causality could depend on acts of synthesis, since they are rules for such syntheses: in Watkins' own words, they are 'laws that are inherent in' the understanding (p. 24). Third, it seems likely that, in order for a 'proper authority' to count as literally prescribing a law through an 'appropriate act', she must be aware of herself as doing so. But particular subjects are presumably not aware of playing any such role with respect to the laws of nature: this is why Kant's Critique has to first hypothesize (Bxvi) and then argue for the revolutionary conclusion that the a priori laws that we discover in nature are 'originally put' there by 'the nature of our mind' (A $\left.{ }_{25}\right) .{ }^{\mathrm{I}}$

Indeed, in the concluding chapter of the book, Watkins clarifies that he does not intend the acts of prescription that underwrite laws of nature to be 'datable historical events' (p. 277). But in that case, how should we understand them? He goes on to say that, in order to make sense of the acts he has in mind, we will have to turn to 'transcendental psychology'. I am not sure how to understand this: perhaps the thought is that the relevant acts of prescription should be regarded as being carried out, not by particular subjects with understanding, but by the faculty of understanding itself. If that is right, however, it seems clear that we are back to speaking metaphorically when we speak of laws of nature being prescribed by the actual acts of an authority.

As part of the same discussion, Watkins also emphasizes the fact that particular acts of the understanding are guided by normative rules. He continues: 'Thus, the acts are crucial insofar as they are responsible for, or are at least indicative of, a distinctive kind of normativity in our judgments about the world and in the world too insofar as it either depends on these judgments or corresponds to them' (p. 278; my emphasis). For the reasons just discussed, both of the first disjuncts in Watkins' description seem too strong: particular acts could not be 'responsible for' the normativity in our judgements about the world, nor could the lawfulness of the world 'depen[d] on' our particular judgements. But if the relevant acts only 'indicate' the norms that govern our judgements, and these norms only 'correspon[d] to' the laws of nature, then speaking of them as acts 
of prescription seems otiose. An act of prescription as it is understood in the natural law tradition is an act in virtue of which a law first becomes obligatory for a domain, not one that merely displays the laws that already govern it. When Kant says that the understanding prescribes laws to nature, then, I contend that we should understand this at least partly metaphorically: as he says elsewhere in the Prolegomena, the principles of possible experience that constitute the laws of the understanding are 'at the same time' $(P, 4: 306)$ simply identical to the universal laws of nature cognized through the understanding - without any need for special acts of prescription.

\section{Empirical Laws of Nature}

A second set of questions concerns the relation between a priori and empirical laws of nature on Watkins' account. Watkins is clear that, although empirical laws present special complications, the generic account of laws he develops is meant to apply to them (pp. 8, 24, 268-9, 273). As he understands them, empirical laws depend on the specific natures of empirical objects for their content and on the understanding for their lawfulness (pp. 24, 273). But this hybrid model seems to result in the reappearance for empirical laws of some of the very problems that Watkins painstakingly addresses for a priori laws.

For one, when it comes to empirical laws, it is not clear how we should understand the relation between what is due to the understanding and what is derived from empirical natures. Watkins presents it as an advantage of the account of causal powers that he develops here and in earlier work $^{2}$ that the necessity of causal relations derives from the natures of the substances that are governed by them. A virtue of this, he argues, is that this necessity 'is not an inexplicable free-floating modality, but rather is based on the natures of things that substances act in accordance with in exercising their causal powers' (p. 34). But if the necessity of empirical causal laws is not determined by the corresponding empirical natures of objects, but rather is prescribed by the understanding, then it seems that the necessity of empirical laws is inexplicably superimposed on them.

Moreover, whereas Watkins argues persuasively that Kant offers a compelling alternative to contemporary views when it comes to the a priori laws of nature, some of the worries he raises for these views threaten to reappear for empirical laws on his account. Watkins discusses two types of contemporary view: empiricist views which take laws of nature to express mere observed regularities between events, and necessitarian views which take them to express necessary relations between universals. 
He identifies significant drawbacks for each kind of view: whereas laws of nature turn out to be contingent on the former, for example, the latter cannot explain how we can come to know necessary relations between universals (pp. 3 I-2). In contrast, Kant's account of a priori laws offers a middle way between these alternatives: these laws express genuine necessities, and since they are due to the subjective principles that are necessary conditions on experience, they are knowable by us a priori (p.33).

But what about empirical laws? On the one hand, since they are laws, they must express objective necessities. On the other hand, since they do not hold in virtue of subjective, necessary conditions on experience, they are not directly accessible to us in the way that a priori laws are. Moreover, as I noted above, their necessity seems to be superimposed on them by the understanding, without a clear account of how it is meant to interact with the empirical natures of the objects involved. Thus the worries about knowability that accompanied the necessitarian view above also seem to loom for empirical laws on Kant's account.

At this point, Watkins might argue that the Critique of the Power of Judgement goes some distance towards explaining our access to empirical laws: it 'attempts to show how a system of laws can reveal the necessity of even empirical laws (even if that necessity is conditional and cannot be confirmed)' (p. 268). But this seems to me stronger than what Kant actually argues for in the third Critique. Kant says there that we must 'regard' (betrachten) nature as governed by a system of empirical laws (FI, 20: 203). However, he makes clear that this does not enable us to cognize any particular empirical system or the empirical laws that figure in it as necessary:

Thus we must think of there being in nature, with regard to its merely empirical laws, a possibility of infinitely manifold empirical laws, which as far as our insight goes are nevertheless contingent $\ldots$ and with regard to them we judge the unity of nature in accordance with empirical laws ... as contingent. But since such a unity must still necessarily be presupposed and assumed ... the power of judgment must thus assume it as an a priori principle for its own use that what is contingent for human insight in the particular (empirical) laws of nature nevertheless contains a lawful unity, not fathomable (ergründende) by us but still thinkable... (CPJ, 5: I 83-4; my emphases) 
If - as this passage suggests - we can only understand particular empirical laws to be contingent, then the worry Watkins identified for empiricist views above also seems to apply to Kant's empirical laws. Thus, depending on how we understand it, we can raise concerns about Kant's account of empirical laws of nature that are similar to concerns Watkins raises for both empiricist and necessitarian accounts.

Now, Watkins suggests that he is content with showing that Kant presents a genuine alternative to contemporary accounts when it comes to a priori laws (p. 35). But this is somewhat unsatisfying. For one thing, the laws of nature that contemporary views seek to account for primarily count as empirical laws for Kant, and so we might wonder to what extent he provides an alternative that is relevant to these views. For another, it can seem like knowledge of Kant's a priori laws (at least those contained in the System of Principles) does not so much amount to knowledge of any particular laws of nature, but rather knowledge that nature is lawful (BI64-5; $P, 4: 3$ I9-20). The law of causality, for example, specifies that all alterations are causally determined (B232), but it does not indicate how we are meant to identify which causal laws determine any particular alteration. But if Kant's account does not put us in a better position to identify any particular laws (setting aside the a priori laws of mechanics), it is not clear how it does much better than the other accounts on offer.

\section{The Immutability of Cognitive Natures}

In comparing Kant's a priori laws with the kind of 'relativized a priori' espoused by Carnap, Watkins argues that a crucial difference between them is that, whereas Carnap's constitutive principles are revisable, Kant's a priori laws depend on the 'immutable' nature of human cognitive capacities (p. 46). That seems right to me, but I wonder how we should understand this immutability. Watkins suggests that although he does not go down this route, Kant 'could still account for a (weaker) notion of constraint by asserting that our natures are immutable, i.e., do not in fact change (even if they could in some sense)' (p. 44, n. I7). However, Kant appears to argue that if the categories were determined merely by what is in fact true of our cognitive natures (even if these natures do not change), this would effectively deprive us of our entitlement to claim that the objects in nature are the way we must think them to be. As he says, if the concept of cause, for example, were a 'subjective predispositio[n] for thinking, implanted in us along with our existence by our author', then: 
I would not be able to say that the effect is combined with the cause in the object: (i.e., necessarily), but only that I am so constituted that I cannot think of this representation otherwise than as so connected; which is precisely what the skeptic wishes most, for then all of our insight through the supposed objective validity of our judgments is nothing but sheer illusion ... one would not be able to quarrel with anyone about that which merely depends on the way in which his subject is organized. ( $\left.\mathrm{B}_{1} 6_{7}-8\right)$

Thus it seems that at least for Kant, the immutability of our cognitive natures must be necessary if the subjective principles that constitute them are to have objective validity, and thus impose any genuine constraints on objects. But what grounds Kant's claim that our natures are necessarily immutable in this way? And how can that claim be reconciled with the following one that Kant also makes about the categories, and that seems to me to be in conflict with it?

But for the peculiarity of our understanding, that it is able to bring about the unity of apperception a priori only by means of the categories and only through precisely this kind and number of them, a further ground may be offered just as little as one can be offered for why we have precisely these and no other functions for judgment or for why space and time are the sole forms of our possible intuition. (BI45-6)

Watkins does not comment on these passages, but they seem to me important for understanding the kind of immutability that attaches to our cognitive capacities for Kant. Further discussion would be helpful in clarifying the extent to which Kant's a priori laws set 'unconditional constraints' on the objects of experience (p. 46).

Notwithstanding the questions I have raised for it here, Kant on Laws presents a compelling and ambitious account of the core conception of law that Kant appeals to in contexts as varied as his epistemology, physics, ethics and teleology. Along the way, Watkins succeeds in situating Kant's account in its historical context, putting it into dialogue with contemporary views, all while resolving a number of thorny questions that have puzzled interpreters. Few have done more than Watkins to extend our understanding of Kant's account of laws of nature and this book is no exception to that impressive record. ${ }^{3}$ 


\section{Notes}

I Translations of Kant's text are from the Cambridge Edition of the Works of Immanuel Kant, ed. Paul Guyer and Allen Wood (Cambridge: Cambridge University Press, I992-). References to Kant's works are given using the volume and page number in the Akademie edition, Kants Gesammelte Schriften, ed. Königlich Preussische Akademie der Wissenschaften, vols I-29, Berlin: de Gruyter, I900-). References to the Critique of Pure Reason are given using the standard $\mathrm{A}$ and $\mathrm{B}$ pagination corresponding to the first and second editions respectively. Other works are referred to using the following abbreviations: $C P J=$ Critique of the Power of Judgement; FI = First Introduction to the Critique of the Power of Judgement; $P=$ Prolegomena to any Future Metaphysics.

2 For example, in Watkins 2005.

3 These comments were delivered at an online book symposium on Kant on Laws in July 2020. I would like to thank Marcus Willaschek for organizing such a stimulating and collegial discussion, and for inviting me to participate. I am grateful to the other participants for their probing comments, and of course to Eric Watkins for his generous and clarifying responses. I also thank Jessica Williams for many enjoyable discussions leading up to the symposium, and Bennett McNulty for his helpful feedback on my commentary.

\section{References}

Watkins, Eric (2005) Kant and the Metaphysics of Causality. Cambridge: Cambridge University Press.

- (2019) Kant on Laws. Cambridge: Cambridge University Press. 